\title{
Prediction of crystal structures and motifs in the Fe-Mg-O system at Earth's core pressures
}

\author{
YANG SUN ${ }^{1}$, RENATA M. WENTZCOVITCH ${ }^{1}$, RENHAI \\ WANG $^{2}$, FENG ZHENG $^{3}$, YIMEI FANG ${ }^{3}$, SHUNQING WU ${ }^{3}$, \\ ZIJIN LIN ${ }^{2}$, CAI-ZHUANG WANG ${ }^{4}$ AND KAI-MING $\mathrm{HO}^{4}$ \\ ${ }^{1}$ Columbia University \\ ${ }^{2}$ University of Science and Technology of China \\ ${ }^{3}$ Xiamen University \\ ${ }^{4}$ Iowa State University \\ Presenting Author: ys3339@columbia.edu
}

$\mathrm{Fe}, \mathrm{Mg}$, and $\mathrm{O}$ are among the most abundant elements in terrestrial planets. While the behavior of the $\mathrm{Fe}-\mathrm{O}, \mathrm{Mg}-\mathrm{O}$, and $\mathrm{Fe}-\mathrm{Mg}$ binary systems under pressure have been investigated, there are still very few studies of the Fe-Mg-O ternary system at relevant Earth's core and super-Earth's mantle pressures. Here, we use the adaptive genetic algorithm (AGA) to study ternary $\mathrm{Fe}_{\mathrm{x}} \mathrm{Mg}_{\mathrm{y}} \mathrm{O}_{\mathrm{z}}$ phases in a wide range of stoichiometries at $200 \mathrm{GPa}$ and $350 \mathrm{GPa}$. We discovered three dynamically stable phases with stoichiometries $\mathrm{FeMg}_{2} \mathrm{O}_{4}, \mathrm{Fe}_{2} \mathrm{MgO}_{4}$, and $\mathrm{FeMg} \mathrm{O}_{4}$ with lower enthalpy than any known combination of Fe-Mg-O highpressure compounds at $350 \mathrm{GPa}$. With the discovery of these phases, we construct the Fe-Mg-O ternary convex hull. We further clarify the composition- and pressure-dependence of structural motifs with the analysis of the AGA-found stable and metastable structures. Analysis of binary and ternary stable phases suggest that $\mathrm{O}, \mathrm{Mg}$, or both could stabilize a $\mathrm{BCC}$ iron alloy at inner core pressures. 